\title{
Thermal aging of heteroatom substituted Keggin type aluminum oxo polycation solutions: Aggregation behavior and impacts on dissolved organic carbon and turbidity removal
}

\author{
Mohammad Shohel*1, Jack A. Smith ${ }^{1}$, Margaret A. Carolan ${ }^{1,2}$, Tori Z. Forbes*1 \\ ${ }^{1}$ Department of Chemistry, University of Iowa, Iowa City, IA-52242 \\ 2Department of Civil and Environmental Engineering, University of Iowa, \\ Iowa City, IA-52242 \\ *Corresponding authors: tori-forbes@uiowa.edu, mohammad-shohel@uiowa.edu
}

\begin{abstract}
Coagulation processes within water treatment plays an important role in contaminant removal and aluminum-oxo Keggin polycations are proved to be an effective coagulating agents. Previous work demonstrated that heteroatom substitution within the Keggin-type polycation $\varepsilon-\mathrm{Al}_{13}$ to form $\varepsilon-\mathrm{GaAl}_{12}$ and $\varepsilon-\mathrm{GeAl}_{12}$ can enhance removal of bacteria, DOC, and turbidity from wastewater. Additional hydrolysis of the $\varepsilon-\mathrm{Al}_{13}$ species to form larger $\mathrm{Al}_{30}$ species has also been shown to improve coagulation, but this aspect has not been evaluated for the $\varepsilon-\mathrm{GaAl}_{12}$ and $\varepsilon^{-}$ $\mathrm{GeAl}_{12}$ systems. In the current study, hydrolysis of $\varepsilon-\mathrm{Al}_{13}, \varepsilon-\mathrm{GaAl}_{12}$ and $\varepsilon-\mathrm{GeAl}_{12}$ was promoted through hydrothermal aging to evaluate the overall solution stability/behavior and water treatment efficiency. Turbidity measurement of aged solution indicated that Ga substituted aluminum-oxo Keggin polycations remain stable in solution and DLS studies demonstrated greater diversity in particle sizes within the system. Additional thermogravimetric analyses of metal hydroxide precipitates formed from the aging studies indicate that the $\mathrm{GaAl}_{12}$ system behaves more like an amorphous $\mathrm{Al}(\mathrm{OH})_{3}$ phase, which has higher solubility than other aluminum hydroxide phases. Hydrothermal aging did not significantly change \%DOC removal as all solution showed high efficiency for removal across a range of $\mathrm{pH}$ values. $\mathrm{GaAl}_{12}$ solutions demonstrated good turbidity removal efficiency in all $\mathrm{pH}$ range, with enhanced performance at $\mathrm{pH}$. The study suggests that larger, relatively stable oligomers do exist within the aged $\mathrm{GaAl}_{12}$ solutions that may contribute to enhanced contaminant removal in a similar manner to what is observed within the $\mathrm{PACl}-\mathrm{Al}_{30}$ coagulant.
\end{abstract}

Keywords: Wastewater treatment, Coagulation, Aluminum-oxo polycation, Heteroatom, Keggin 
Introduction

Coagulation and flocculation are crucial processes for wastewater treatment and rely on

39 the addition of chemical agents to remove impurities from the water. Wastewater contains dissolved and suspended particles that must be removed before recharge into natural waters. The

41 suspended particles are typically composed of clay, natural organic matter, etc., whereas the 42 dissolved component contains a range of molecular inorganic (i.e. $\mathrm{Na}^{+}, \mathrm{K}^{+}, \mathrm{Ca}^{2+}, \mathrm{PO}_{4}^{3-}, \mathrm{CO}_{3}^{2-}, \mathrm{Cl}^{-}$

43 ) and organic species, including some trace contaminants (i.e. heavy metals herbicides, pesticides, 44 pharmaceuticals) that are harmful to human health and the natural environment. To remove these 45 species, coagulation agents are added to the water to aggregate and/or flocculate the suspended 46 and dissolved particles. These flocculants can physically be separated within the water treatment 47 facility to remove them before recharge.

Over the past 20 years, efforts to improve coagulation agents have turned away from simple metal salts and towards partially-hydrolyzed polyaluminum nanoclusters. The most widely used coagulation agents are based upon the hydrolysis $\mathrm{Al}^{3+}$ and $\mathrm{Fe}^{3+}$ salts, such as alum and ferric 51 chloride. Addition of these metals to water at a circumneutral $\mathrm{pH}$ results in hydrolysis of the metal 52 cation to larger nanoscale polyaluminum species and can be used for aggregation of the 53 flocculant. ${ }^{1,2}$ Structurally, these polyaluminum cations are based upon the formation of 1-2 nm 54 Keggin-type clusters, with the exact solution speciation dependent on synthetic conditions. The 55 Keggin-type structural topology consists of a central tetrahedrally coordinated $\mathrm{Al}^{3+}$ cation 56 surrounded by twelve additional $\mathrm{Al}^{3+}$ in octahedral coordination to form $\sim 1 \mathrm{~nm}$ size $57 \quad\left[\mathrm{AlO}_{4} \mathrm{Al}_{12}(\mathrm{OH})_{24}\left(\mathrm{H}_{2} \mathrm{O}\right)_{12}\right]^{7+}\left(\mathrm{Al}_{13}\right)$ species. ${ }^{3}$ Initially the $\mathrm{Al}^{3+}$-bearing solutions undergo partial 58 hydrolysis to form the $\varepsilon-\mathrm{Al}_{13}$ isomer and additional aging results in the creation of $\mathrm{Al}_{13}$ isomers $(\delta$ - 
$\left.\mathrm{Al}_{13}, \gamma-\mathrm{Al}_{13}\right)$ and larger $\sim 2 \mathrm{~nm}$ oligomers $)\left[\mathrm{Al}_{2}\left(\mu_{4}-\mathrm{O}_{8}\right)\left(\mathrm{Al}_{24}\left(\mu_{2}-\mathrm{OH}\right)_{50}\left(\mathrm{H}_{2} \mathrm{O}\right)_{20}\right]^{12+}\left(\mathrm{Al}_{26}\right)\right.$,

60

$\left[\mathrm{Al}_{30} \mathrm{O}_{8}(\mathrm{OH})_{56}\left(\mathrm{H}_{2} \mathrm{O}\right)_{24}\right]^{18+}\left(\mathrm{Al}_{30}\right)$ and $\left.\left[\mathrm{Al}_{32} \mathrm{O}_{8}(\mathrm{OH})_{60}\left(\mathrm{H}_{2} \mathrm{O}\right)_{28}\left(\mathrm{SO}_{4}\right)_{2}\right]^{16+}\left(\mathrm{Al}_{32}\right)\right) .^{3-6}$

Polyaluminum coagulants are currently on the market (i.e. PAC, PACI, and ACH) and demonstrate higher performance compared to alum and ferric chloride. Each polyaluminum nanocluster possesses a high positive charge that can more effectively attract the negatively charged contaminants to form neutral flocculants and also physically trap neutral or cationic species in the aggregation process. This means the partially hydrolyzed coagulant is effective at lower dosages, has a wider operational range at different condition $(\mathrm{pH}$, temperature, colloids concentration, etc.), and better floc formation. ${ }^{7-10}$ For example, Mertens et al. 2012 reported PACl coagulants with higher $\mathrm{Al}_{30}$ content performed best at removing $\mathrm{As}(\mathrm{V})$ from natural well water $(20-2300 \mu \mathrm{g} / \mathrm{L})$ to levels that are below the World Health Organization guideline of $10 \mu \mathrm{g} / \mathrm{L} .{ }^{11}$ In addition, polyaluminum based coagulants have also shown enhanced performance for treatment of natural organic matter, bacteriophage and clay particlesfrom wastewater. ${ }^{12-16}$ Very recently, Wang and co-workers have also shown the use of polyaluminum coagulants in removing dyes, antibiotics and even model microplastics from wastewater. ${ }^{17,18}$

Heteroatom substitution of the polyaluminum nanoclusters results in subtle variabilities of the surface chemistry and can give rise to improved coagulation. Both $\mathrm{Ga}^{3+}$ and $\mathrm{Ge}^{4+}$ readily substitute into the central tetrahedral site within the $\varepsilon-\mathrm{Al}_{13}$ topology to create the $\left[\mathrm{GaO}_{4} \mathrm{Al}_{12}(\mathrm{OH})_{24}\left(\mathrm{H}_{2} \mathrm{O}\right)_{12}\right]^{7+}\left(\mathrm{GaAl}_{12}\right)$ and $\left[\mathrm{GeO}_{4} \mathrm{Al}_{12}(\mathrm{OH})_{24}\left(\mathrm{H}_{2} \mathrm{O}\right)_{12}\right]^{7+} \quad\left(\mathrm{GeAl}_{12}\right)$ species, respectively. ${ }^{19,20}$ Coagulation behavior of the $\varepsilon-\mathrm{GaAl}_{12}$ and $\varepsilon-\mathrm{GeAl}_{12}$ species was performed by Stewart et al. and the authors demonstrated the importance of this single atom substitution in $\varepsilon$ $\mathrm{Al}_{13}$. Contaminant removal efficacy of bacteriophage, Cryptosporidium, and dissolved organic 
81 carbon (DOC) for heteroatom substituted $\varepsilon$-Keggin isomers indicated that a trend where the 82 polyaluminum clusters could be ranked $\varepsilon-\mathrm{GaAl}_{12}>\varepsilon-\mathrm{Al}_{13}>\varepsilon-\mathrm{Ge} \mathrm{Al}_{12}$.

While the performance of polyaluminum species in PACl coagulation behavior has been

84 evaluated, less is known regarding clusters with heteroatomic substitution. The study by Stewart 85 et al. focused solely on $\varepsilon-\mathrm{Al}_{13}$ and related $\varepsilon-\mathrm{MAl}_{12}\left(\mathrm{M}=\mathrm{Ga}^{3+}\right.$ and $\left.\mathrm{Ge}^{4+}\right)$ clusters in the removal of 86 suspended and dissolved solids. Additional heteroatom oligomers were also recently identified in 87 thermally aged $\mathrm{GaAl}_{12}$ and $\mathrm{GeAl}_{12}$ bearing solutions and resulted in the isolation of several novel 88 species $\left(\delta-\mathrm{GaAl}_{12}, \mathrm{Ga}_{2} \mathrm{Al}_{18}, \mathrm{Ga}_{2.5} \mathrm{Al}_{28.5}, \mathrm{Ge}_{4} \mathrm{Al}_{48}, \delta-\mathrm{Cr}_{\mathrm{n}} \mathrm{Al}_{13-\mathrm{n}}\right) .{ }^{21-24}$ These heteroatomic clusters 89 have similarities to the $\delta-\mathrm{Al}_{13}$ and $\mathrm{Al}_{30}$ phase observed in some $\mathrm{PACl}$ coagulants, but have not 90 been evaluated for enhanced coagulation performance. Aggregation behavior is also an important 91 piece that contributes to higher performance of coagulants and controls shelf-life for these 92 commercial products, but a detailed understanding of these processes is lacking within heteroatom 93 Al-Keggin systems. In the current study, we evaluate solutions of as-synthesized $\mathrm{MAl}_{12}(\mathrm{M}=\mathrm{Al}, \mathrm{Ga}$ and $\mathrm{Ge})$ 95 clusters that are analogous to commercial coagulate agents. We have hydrothermally aged these 96 solutions for 0 to 7 days to explore their overall aggregation behavior as it relates to formation of 97 oligomeric Keggin-type species. We then evaluated initial assessment of their water treatment 98 efficiency through the comparison of DOC and turbidity removal capacity of different $\mathrm{MAl}_{12}$ 99 solutions between a pH range 5-9 using humic acid and kaolin spiked Iowa river water. The result 100 of heteroatom substitution on stability and particle size distribution of aged Keggin solution were 101 evaluated using pH, turbidity, and Dynamic Light Scattering (DLS) measurements. The solid 102 precipitates formed during hydrothermal aging of Keggin solution s were characterized using 
103 Powder X-ray diffraction (PXRD), Thermogravimetric Analysis (TGA) and Scanning Electron

104 Microscopy-Energy Dispersive X-ray Spectroscopy (SEM-EDS).

106 Experimental

107 Scientific), anhydrous $\mathrm{GaCl}_{3}$ (Strem Chemicals), $\mathrm{GeO}_{2}$ (Beantown Chemicals), Humic Acid (Sigma-Aldrich) and Kaolin (Beantown Chemicals)) were used as received. Solution utilized in this study were prepared using ultrapure water (18.2 M $\Omega . \mathrm{cm}$, Easypure II) as the solvent.

The $\mathrm{Al}_{13}$ stock solution was prepared by following Johansson et al. ${ }^{25}$ This is the same 114 protocol that is used typically in preparing Keggin-type polyaluminum coagulants ( $\mathrm{PACl}-\mathrm{Al}_{13}$ and

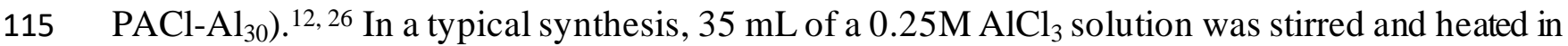
a $250 \mathrm{~mL}$ glass Erlenmeyer flask on water bath until the temperature was stabilized at $80^{\circ} \mathrm{C}$. Upon

117 thermal equilibration of the solution, $84 \mathrm{~mL} \mathrm{NaOH}(0.25 \mathrm{M})$ was added dropwise under constant 118 stirring. The solution was then cooled to room temperature for use in additional experiments. A $\mathrm{GaAl}_{12}$ solution was prepared by following procedure of Parker et al. ${ }^{19}$ with further 120 modification by Shohel et al. ${ }^{21}$ The stock solution of containing mixed $\mathrm{Al}^{3+}$ and $\mathrm{Ga}^{3+}$ cations in a $1216: 1$ molar ration was formed by combining $30 \mathrm{~mL}$ of $\mathrm{AlCl}_{3}(0.25 \mathrm{M})$ and $5 \mathrm{~mL}$ of $\mathrm{GaCl}_{3}(0.25 \mathrm{M})$ 122 in a $250 \mathrm{~mL}$ glass Erlenmeyer flask. This solution was heated in a water bath to $80^{\circ} \mathrm{C}$ and partial 123 hydrolysis of the heteroatom solution occurred through the addition of $84 \mathrm{~mL}$ of $\mathrm{NaOH}(0.25 \mathrm{M})$ 124 in a dropwise fashion under constant stirring. 
Similarly, the $\mathrm{GeAl}_{12}$ stock solution prepared by following Lee et al. ${ }^{20}$ with further

modification adopted from Shohel et al. ${ }^{23}$ Initially a $\mathrm{Ge}^{4+}$ stock solution was prepared by adding $0.088 \mathrm{~g} \mathrm{GeO}_{2}$ to $96 \mathrm{~mL}$ of $\mathrm{NaOH}(0.25 \mathrm{M})$ with constant stirring for 20 minutes. This solution was then utilized to partially hydrolyze $40 \mathrm{~mL}$ of $0.25 \mathrm{M} \mathrm{AlCl}_{3}$ under constant stirring at $80{ }^{\circ} \mathrm{C}$.

Thermal aging of the stock solutions occurred by loading $15 \mathrm{ml}$ of the prepared $\mathrm{MAl}_{12}(\mathrm{M}$ $=\mathrm{Al}^{3+}, \mathrm{Ga}^{3+}$, and $\mathrm{Ge}^{4+}$ ) stock solutions into individual $125 \mathrm{~mL}$ Teflon-lined Parr vessels and heated in a gravimetric oven set at $90{ }^{\circ} \mathrm{C}$. As-prepared/unaged solutions are designated as 0 day and then additional hydrothermal aging was completed for 1, 3, and 7 days.

Solution $\mathrm{pH}$ and turbidity of all aged and unaged $\mathrm{MAl}_{12}$ samples were measured using a VWR SB70P pH probe and Hach $2100 \mathrm{~N}$ turbidity meter, respectively. Hydrodynamic diameter of $\mathrm{MAl}_{12}$ species in solution was analyzed by Malvern Zetasizer NanoZS. Both $\mathrm{Al}_{13}$ and $\mathrm{GaAl}_{12}$ solutions were filtered through a $0.45 \mu \mathrm{m}$ membrane filter prior to DLS measurement to analyze the suspended solids. For $\mathrm{GeAl}_{12}$, an extra filtration step with a $0.25 \mu \mathrm{m}$ membrane filter was necessary due to presence of large amount of solid precipitate that formed in this system. During DLS measurement, at least 20 individuals scan were performed to determine particles size distribution within each solution.

Precipitates were separated from the 7-14 days aged $\mathrm{MAl}_{12}$ solution by centrifugation and washed with deionized water. The collected solids were dried in oven at $45^{\circ} \mathrm{C}$ for 48 hours and then characterized by quantitative gravimetric analysis, Powder X-Ray Diffraction (PXRD), Scanning Electron Microscopy-Energy Dispersive X-ray Spectroscopy (SEM-EDS) and Thermogravimetric Analysis (TGA). Quantitative gravimetric analysis was performed on precipitates separated from $\mathrm{MAl}_{12}$ aged (14 days) solutions with a Metler Toledo AT20 analytical microbalance. PXRD of samples were performed using Bruker D8 Discover Diffractometer 
148 equipped with $\mathrm{Cu} \mathrm{K \alpha}(\lambda=1.5406 \AA)$ radiation and multimode EIGER2R detector. Solid samples 149 were deposited on a zero-background silicon wafer and the data was collected from $10-80^{\circ} 2 \theta$ with 150 a step size of $0.2^{\circ}$ and a count time of $5 \mathrm{sec} / \mathrm{step}$. Thermal stability and dehydration of the collected 151 solids were determined by placing 5-10 mg into an aluminum pan and heating on a TA instruments 152 Q500 thermogravimetric analyzer (TGA) at a ramp rate of $10{ }^{\circ} \mathrm{C} / \mathrm{min}$. Weight loss data was 153 collected from $20{ }^{\circ} \mathrm{C}$ to $600{ }^{\circ} \mathrm{C}$ using high purity $\mathrm{N}_{2}$ as the carrier gas. SEM-EDS was used to 154 image and qualitatively assess elemental composition of carbon-coated precipitates. The samples 155 were placed on a Hitachi S-3400N system equipped with silicon drift detector (XFlash, Bruker $156 \mathrm{AXS}$ ) and measurements were carried out at $15 \mathrm{kV}$ beam energy with a 2.5 minute exposure time 157 and $10 \mathrm{~mm}$ of working distance.

Water treatment: DOC removal and Turbidity

Natural water used for water treatment experiments was collected from Iowa river near the 161 University of Iowa campus in February 2020. The physical parameter of collected river water was 162 measured for the overall sample $(\mathrm{pH}=7.95$, turbidity before settling $=20.0$, turbidity after settling 16324 hours $=3.60, \mathrm{UV}-\mathrm{Vis}$ absorption at $254 \mathrm{~nm}=0.0656)$. Water quality parameters for the 164 collection site of Iowa river is provided by the Iowa Department of Natural resources (Supporting 165 Information Table S2). Settled river water was used for water treatment experiments in accordance 166 with previous studies. ${ }^{15,27}$

Humic acid was used to evaluate DOC removal efficiency of aged and unaged $\mathrm{MAl}_{12}$ 168 solutions at $\mathrm{pH}=5,6,7,8$, and 9. A stock solution of humic acid with concentration $1.0 \mathrm{~g} / \mathrm{L}$ was 169 prepared in water and filtered with Whatman $®$ filter paper (Grade: 1 , diameter: $100 \mathrm{~mm}$, pore size: $17011 \mu \mathrm{m})$. Following filtration, $21 \mathrm{~mL}$ of the stock humic acid solution was then homogeneously 
171 mixed with $140 \mathrm{~mL}$ of river water. The $\mathrm{pH}$ of the Humic Acid spiked River Water (HARW) was

172 then adjusted into desired value using few drops of $1 \mathrm{M}$ or $0.25 \mathrm{M}$ aqueous $\mathrm{HCl}$ and $\mathrm{NaOH}$. The

173 absorption spectra of the HARW solution was collected in quartz cuvette on a Cary 5000 UV

174 spectrometer (Agilent technology). The $254 \mathrm{~nm}$ wavelength was used to evaluate DOC content. ${ }^{28}$

175 This $\mathrm{pH}$ adjusted HARW sample before flocculation experiments had measurable absorption

176 values $\sim 0.80$ at $254 \mathrm{~nm}$ in the UV/Vis spectrum. For the DOC removal experiments, $10 \mathrm{~mL}$ of the

177 HARW solution was placed into separate $20.0 \mathrm{~mL}$ glass scintillation vials, followed by addition

178 of $25 \mu \mathrm{L}$ of the prepared $\mathrm{MAl}_{12}$ solutions. These solutions were then stirred for 25 minutes with a

179 magnetic stir bar $(15.9 \times 8 \mathrm{~mm})$ at $200 \mathrm{rpm}$ for the overall flocculation reaction. The generated

180 flocs were initially separated by centrifugation at $6000 \mathrm{rpm}$, followed by a secondary filtration

181 using $0.45 \mu \mathrm{m}$ membrane filter. The absorption spectra of treated water and HARW solution was

182 collected and the \% DOC removal for all samples as outlined by Weishaar et al. ${ }^{28}$

183 To evaluate turbidity removal, $55 \mathrm{mg}$ of kaolin was added to $660 \mathrm{~mL}$ river water in a 1.5

184 L glass jar and shaken vigorously for five minutes. The $\mathrm{pH}$ of the solution was then adjusted to the

185 desired value using $1 \mathrm{M}$ or $0.25 \mathrm{M}$ aqueous $\mathrm{HCl}$ and $\mathrm{NaOH}$. Turbidity of stock solution was

186 initially measured using a Hach $2100 \mathrm{~N}$ turbidity meter to be 90 nephelometric turbidity units

187 (NTU). The impact of the polyaluminum clusters on solution turbidity was evaluated by adding

$1881.0 \mathrm{~mL}$ of each $\mathrm{MAl}_{12}$ solution into a separate $50 \mathrm{~mL}$ aliquot of the prepared kaolin spiked river

189 water in a $60 \mathrm{~mL}$ transparent reagent bottle with a magnetic stir bar $(15.9 \times 8 \mathrm{~mm})$. This solution

190 was initially mixed for one minute at $400 \mathrm{rpm}$ and then stirred for an additional 10 minutes at 100

$191 \mathrm{rpm}$. Generated flocks were then allowed to separate via gravitational settling over the course of

19240 minutes before $30 \mathrm{~mL}$ of the solution was carefully removed from bottle using a pipette. The

193 solution from the top $0.5 \mathrm{~cm}$ and bottom $2.0 \mathrm{~cm}$ were not sampled so that the solution represented 
194 the residual turbidity measurement. These solutions were again analyzed using a Hach $2100 \mathrm{~N}$ 195 turbidity meter.

Result and Discussion

Characterization of $M A l_{12}$ solutions

$\mathrm{MAl}_{12}$ solutions remained within in a relatively narrow $\mathrm{pH}$ range (3.50-4.47), but decreased slightly with hydrothermal aging due to the extended hydrolysis reaction of polyaluminum species

(Figure 1A). Continued hydrolysis brought about by aging of the solution leads to the release of $203 \mathrm{H}^{+}$from deprotonation of surface water groups and formation of bridging hydroxyl groups. 204 Previous work by Casey and coworkers demonstrated that the acidity of the ligated water 205 molecules varies as a function of the heteroatom substitution with $\mathrm{GaAl}_{12}<\mathrm{Al}_{13}<\mathrm{GeAl}_{12}$ and this 206 was confirmed with computational results by Bjorklund et al. ${ }^{29,30}$ The largest $\mathrm{pH}$ differences for 207 all three samples were observed between 0 to 1 day $(2.75-7.20 \%)$ and then from 1 to 3 days 208 (2.59-5.89\%). The smallest difference in the solution $\mathrm{pH}$ was observed between 3 to 7 days (1.03 $209-2.41 \%$ ), suggesting that the forward reaction for the oligomerization process was likely nearing 210 equilibrium. Turbidity of $\mathrm{MAl}_{12}$ solutions during hydrothermal aging varied significantly, with visible 212 differences observed for the heteroatom substitution. All initial $\mathrm{MAl}_{12}$ solutions were visibly clear 213 with no observable precipitate at the bottom of the vial prior to the aging process. This was also 214 confirmed by turbidity measurements with values of 0.50- 0.85 NTU. Upon hydrothermal aging, 215 increased turbidity was noted for the $\mathrm{Al}_{13}$ and $\mathrm{GeAl}_{12}$ solutions, whereas the $\mathrm{GaAl}_{12}$ aged solutions 216 visibly remained clear (Figure 1C). The NTU values for the $\mathrm{MAl}_{12}$ solutions reveals that the 
$217 \mathrm{GeAl}_{12}$ solutions are more turbid than $\mathrm{Al}_{13}$ at the same time points (Figure 1B). We have also 218 noted that although $\mathrm{GaAl}_{12}$ aged solutions are visibly transparent, turbidity measurements 219 indicated a small increase with aging time (2.00- 5.65 NTU). Colloidal particles for all $\mathrm{MAl}_{12}$ 220 solutions aggregated at the bottom of the vial if left undisturbed for two days. The gravimetric 221 analysis of precipitates formed after 14 days of aging have also shown formation of more insoluble 222 matter for $\mathrm{GeAl}_{12}$ solution with quantified mass of $115.85 \pm 16.85 \mathrm{mg}$ (Figure 1D). Whereas, $223 \mathrm{GaAl}_{12}$ solution formed only $2 \pm 0.02 \mathrm{mg}$ precipitates and $39.1 \pm 2.9 \mathrm{mg}$ were recovered from the $224 \quad \mathrm{Al}_{13}$ solution.

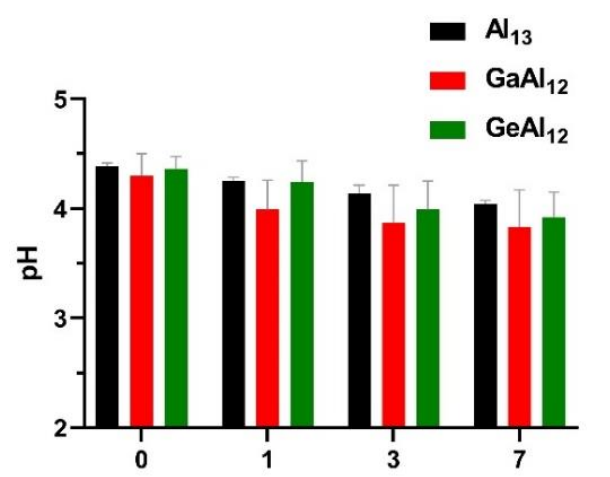

Days Aged at $90{ }^{\circ} \mathrm{C}$

(A)

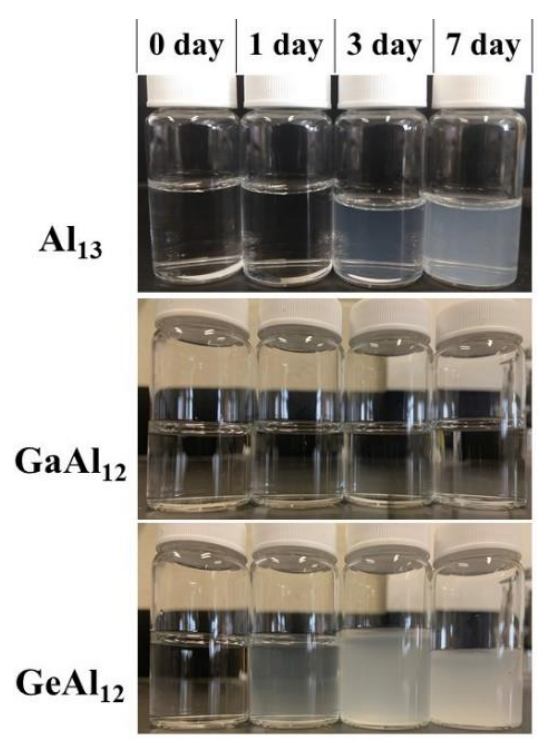

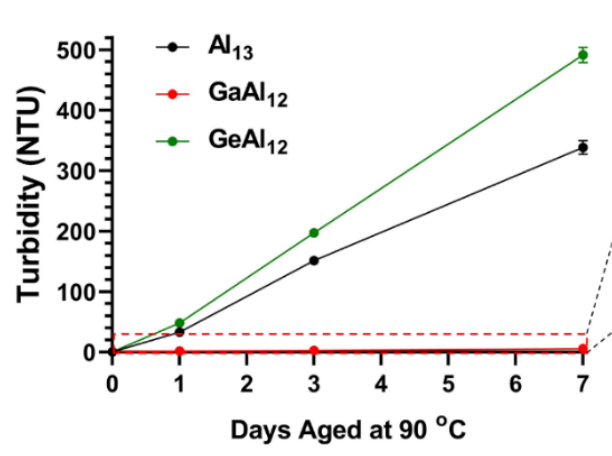

(B)
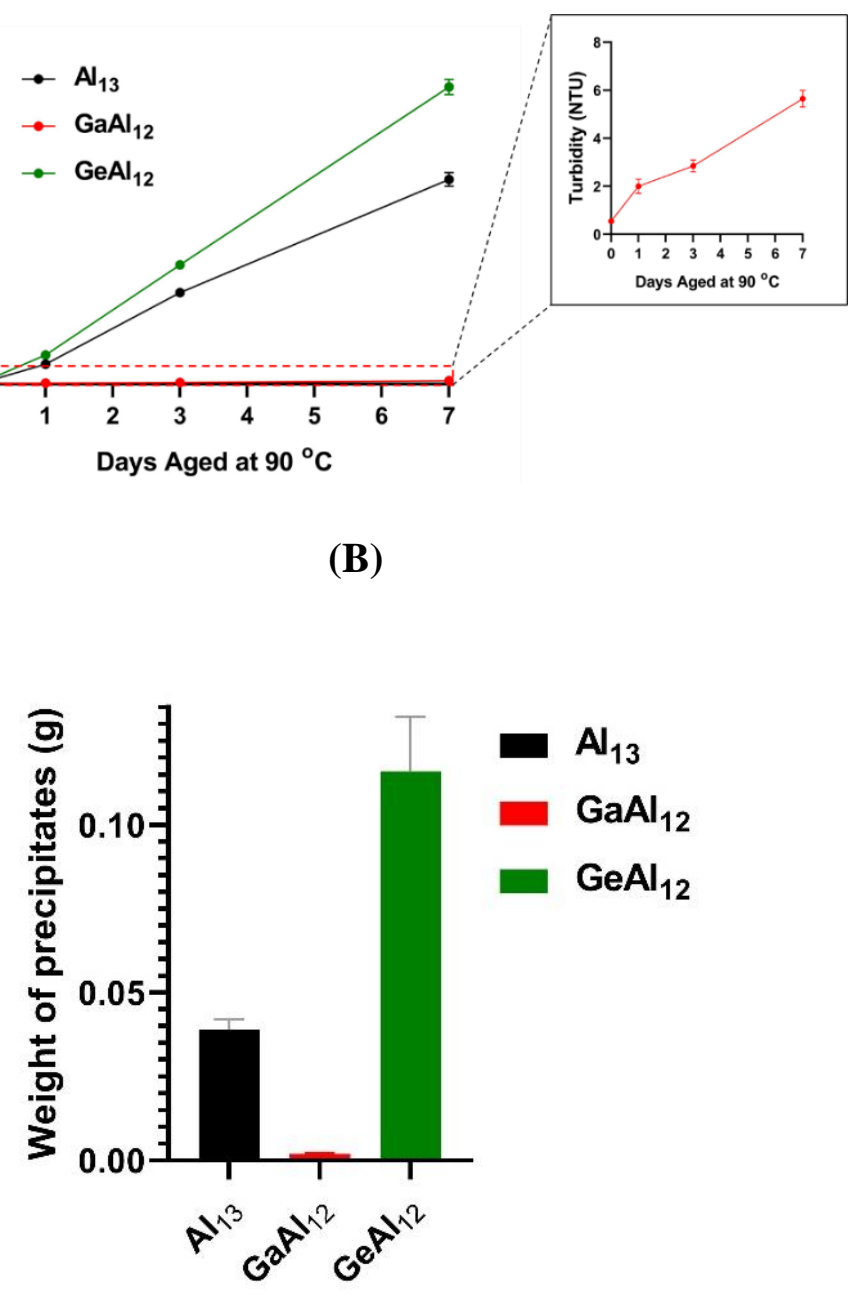
Figure 1. The (A) pH, (B) turbidity, (C) physical appearance and (D) mass of precipitates recovered from $\mathrm{MAl}_{12}$ solutions during hydrothermal aging at $90{ }^{\circ} \mathrm{C}$.

226 size in filtered $\mathrm{MAl}_{12}$ solutions and probe formation of polyaluminum species. It is important to

227 note that colloidal species scatter with higher intensity than smaller polyaluminum species is

228 solution; ${ }^{31,} 32$ thus, we utilize this technique to compare differences in particle size distribution

229 between the pure $\mathrm{Al}_{13}$ and $\mathrm{Ge}^{4+}$ - or $\mathrm{Ga}^{3+}$-substituted version and not relative amounts of the

230 particles in the solution. For unaged $\mathrm{Al}_{13}$ solution there are two peaks, with the feature at $1.5 \mathrm{~nm}$

231 corresponding to the hydrodynamic diameter of the $\mathrm{Al}_{13}$ Keggin-type species and a second one at

$232>100 \mathrm{~nm}$ that belongs to $\mathrm{Al}(\mathrm{OH})_{3}$ colloids. Upon aging, the peak at $1.5 \mathrm{~nm}$ disappeared and only

233 the colloidal species $(>100 \mathrm{~nm})$ remained in solution. For unaged $\mathrm{GaAl}_{12}$ solution, we have

234 observed multiple peaks in $<100 \mathrm{~nm}$ range with center at hydrodynamic diameter $1.5,8$, and 72

$235 \mathrm{~nm}$. After one and three days of aging, the peak at $1.5 \mathrm{~nm}$ remained in the size plot, but the second 236 peak shifted to $11.7 \mathrm{~nm}$. The $1.5 \mathrm{~nm}$ peak was not present after 7 days of aging $\mathrm{GaAl}_{12}$ solution,

237 but peaks at $11.7 \mathrm{~nm}$ and $60 \mathrm{~nm}$ were present in the size plot. For $\mathrm{GeAl}_{12}$, the unaged solution has

238 two features in the $<100 \mathrm{~nm}$ region: one centered at $1.3 \mathrm{~nm}$ and a second, broad peak at 239 approximately $15 \mathrm{~nm}$. After thermal aging the $\mathrm{GeAl}_{12}$ solution, a feature at $2.8 \mathrm{~nm}$ on day 3 appears 240 and becomes more intense after 7 days of treatment.

241 Based upon our current understanding of the known $\mathrm{Al}^{3+}$ polycation species, we can 242 tentatively assign the peaks observed in the DLS. The peak in unaged $\mathrm{Al}_{13}$ and $\mathrm{GaAl}_{12}$ solution at 243 approximately $1.5 \mathrm{~nm}$ aligns well with the expected hydrodynamic diameter for the known 
244 polyaluminum species $\mathrm{Al}_{13}, \mathrm{Al}_{30}, \mathrm{GaAl}_{12}$ or $\mathrm{Ga}_{2.5} \mathrm{Al}_{28.5}$ species in solution. ${ }^{21,33-35}$ Features at $8 \mathrm{~nm}$ 245 and $15 \mathrm{~nm}$ for unaged $\mathrm{GaAl}_{12}$ and $\mathrm{GeAl}_{12}$ solution may correspond to the aggregation of smaller 246 clusters. For the $\mathrm{GeAl}_{12}$ solutions, the peak at $1.3 \mathrm{~nm}$ can be correlated to a $\mathrm{GeAl}_{12} \mathrm{species}$ and the 247 feature at $2.8 \mathrm{~nm}$ have been reported due to the formation of the $\mathrm{Ge}_{4} \mathrm{Al}_{48}$ species from condensation 248 of $\mathrm{GeAl}_{12 .}{ }^{23} \mathrm{In}$ addition, all three systems contain particles with sizes greater than $10 \mathrm{~nm}$ that 249 contribute to the turbidity of the system and are likely associated with aggregated Keggin-type 250 particles.

251

252

253

254 


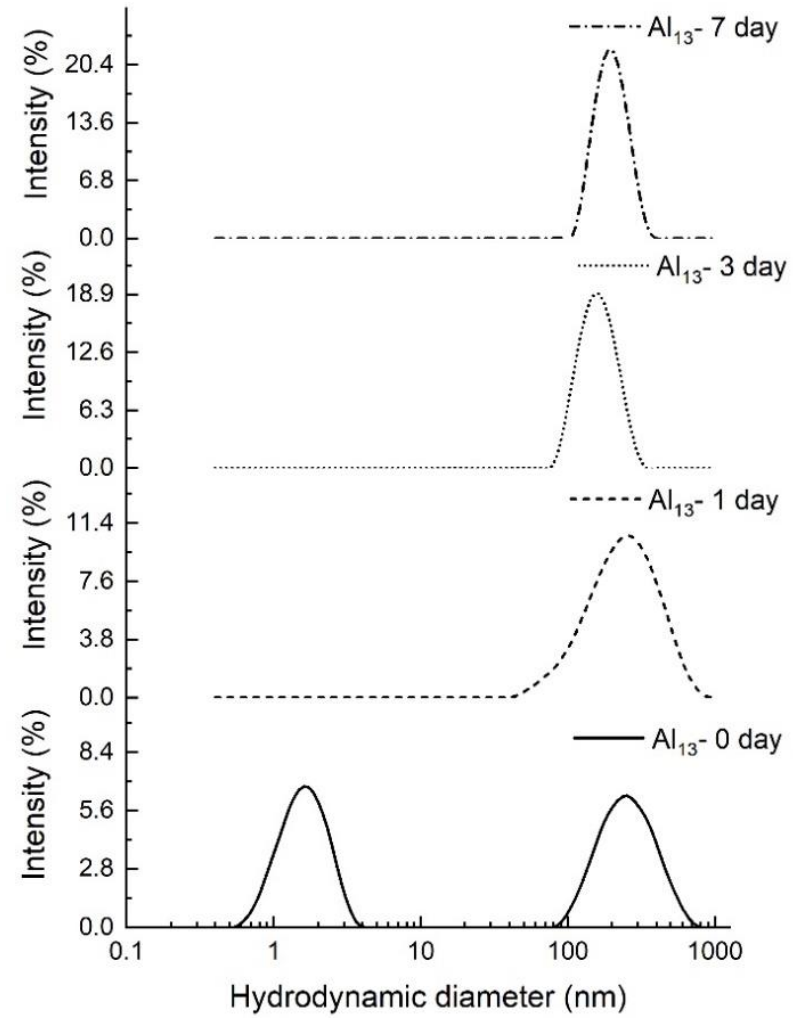

(A)

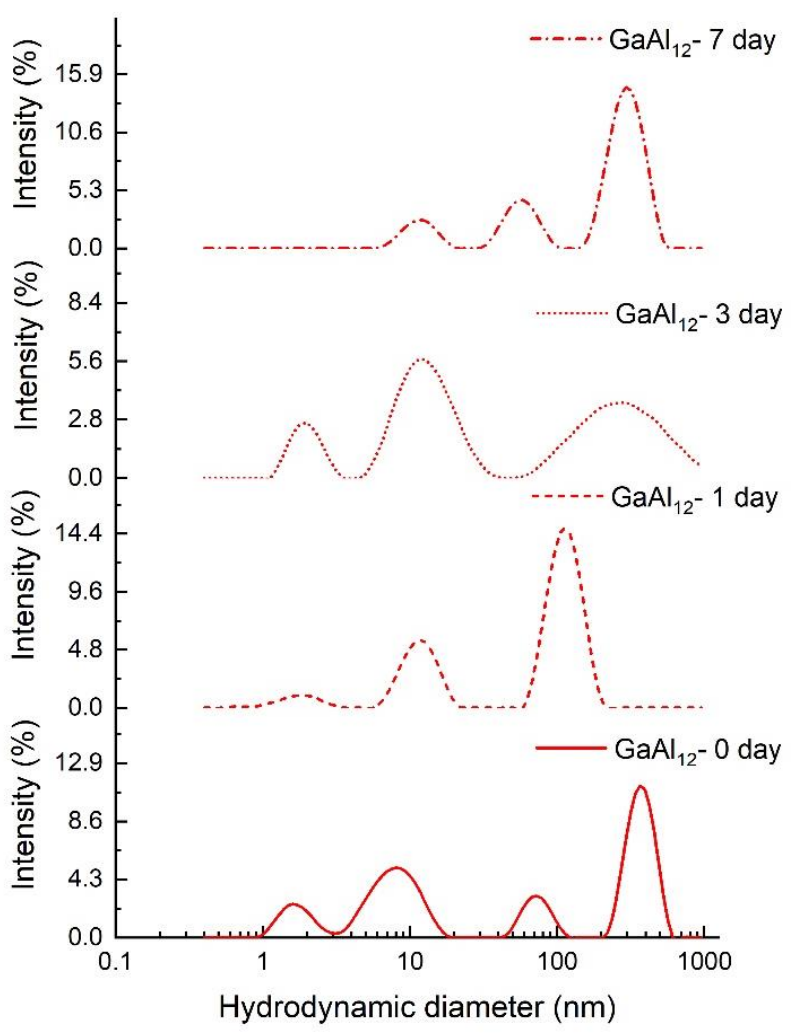

(B)

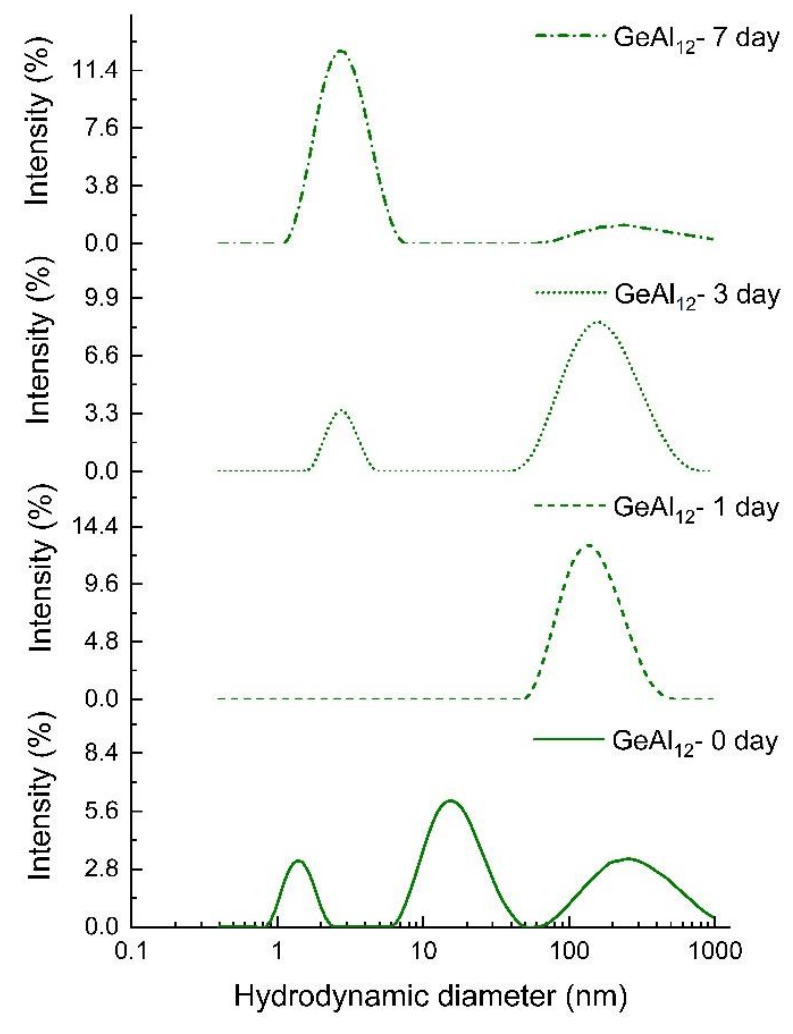

(C)

Figure 2. Particle size distribution from DLS measurement in aged and unaged solution of (A) $\mathrm{Al}_{13},(\mathbf{B}) \mathrm{GaAl}_{12}$ and $(\mathbf{C}) \mathrm{GeAl}_{12}$. 

273 obtained from the SEM-EDS, we can say that the $\mathrm{Ga}^{3+}$ and $\mathrm{Ge}^{4+}$ contents are enriched (Al:Ga ratio $274=12: 3.8$ and $\mathrm{Al}: \mathrm{Ge}$ ratio $=12: 2$ with $\mathrm{Al}: \mathrm{M}=12: 1$ for $\mathrm{MAl}_{12}$ Keggin) in the precipitate.

\section{Characterization of precipitates formed from the $M A l_{12}$ system.}

Changes in turbidity within the $\mathrm{Al}^{3+}$ system is caused by nucleation and precipitation of solid hydroxide phases. To further explore the solid precipitate, we performed additional chemical characterization of the insoluble flocculant to provide a deeper insight into the structure and composition. The PXRD of all precipitates contain a broad feature below $15^{\circ} 2 \theta$ value, suggesting formation of an amorphous material (Figure S1). There are small sharp peaks located at 27.38, $31.72,45.46$, and $56.48^{\circ} 2 \theta$ value for all precipitates due to the presence of $\mathrm{NaCl}$ salts that crystalize during sample drying. Morphological analysis of the particles observed with SEM suggest the presence of both micron and submicron particles in all precipitates (Figure S2). EDS analysis identifies the presence of $\mathrm{Al}, \mathrm{O}, \mathrm{Na}$ and $\mathrm{Cl}$ in the precipitate obtained from $\mathrm{Al}_{13}$ solution (Table S1), corroborating our PXRD analysis. EDS also indicated that Ga and Ge were both associated with precipitates collected from $\mathrm{GaAl}_{12}$ and $\mathrm{GeAl}_{12}$ solutions, respectively. Given the incorporation of $\mathrm{Ga}$ and $\mathrm{Ge}$ into the Keggin-type topology, we hypothesized that similar ratios would be observed within the amorphous material. Based upon the semi-quantitative amounts

We have also observed difference in TGA patterns among precipitates collected from different $\mathrm{MAl}_{12}$ solutions. All the precipitates continuously lost $27.9-33.6 \%$ weight as the temperature increased from 20 to $600^{\circ} \mathrm{C}$ (Figure 3A and 3B). The derivative weight loss indicates that the precipitates have two observable two weight loss steps, with the first occurring between 30-150 ${ }^{\circ} \mathrm{C}$ for a total decrease of $6.9,12.1$, and 10.3 wt. \% for $\mathrm{Al}_{13}, \mathrm{GeAl}_{12}$, and $\mathrm{GaAl}_{12}$, respectively. The second weight loss for these samples occur between $230-520{ }^{\circ} \mathrm{C}$ for both $\mathrm{Al}_{13}$ 
and $\mathrm{GeAl}_{12}$ precipitates with a decrease of $14.3 \%$ and $13.9 \%$, respectively. This second step occurs

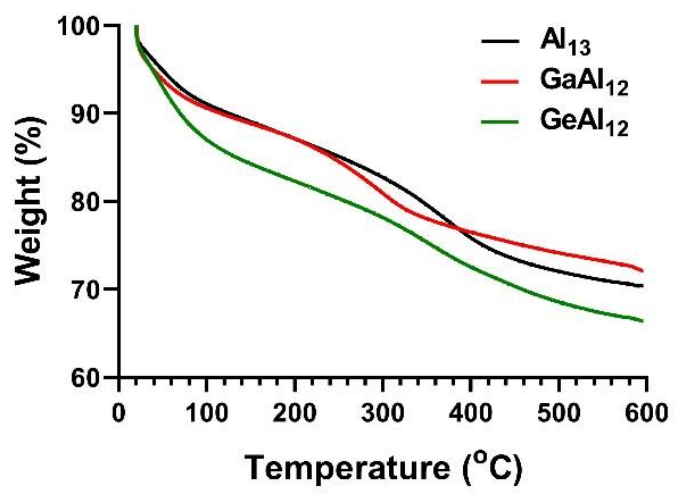

(A)

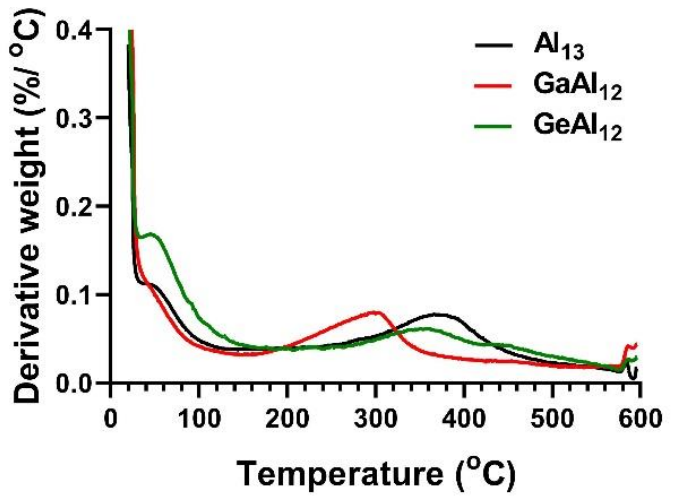

(B)

284 Figure 3. (A) Thermogravimetric pattern and (B) Derivative thermogravimetric (DGT) plot of precipitate formed during thermal aging of $\mathrm{MAl}_{12}$ solution.

Similar TGA results have also been reported for the $\mathrm{Al}^{3+}$ system. Two weight loss steps

287 have been reported earlier for different $\mathrm{Al}(\mathrm{OH})_{3}$ phases, with first one occurring between $30-140^{\circ} \mathrm{C}$ 288 and corresponding to removal of surface adsorbed water, and the second weight loss $\left(>200^{\circ} \mathrm{C}\right)$ 289 correspond to removal of hydroxyl groups to form $\mathrm{Al}_{2} \mathrm{O}_{3} \cdot{ }^{36,37}$ The second weight loss steps varied 290 for different $\mathrm{Al}(\mathrm{OH})_{3}$ phases and their synthesis condition. Sato reported that the second weight 291 loss occurred between $290-350^{\circ} \mathrm{C}$ for amorphous $\mathrm{Al}(\mathrm{OH})_{3}, 400-500^{\circ} \mathrm{C}$ for pseudoboehmite $292\left((\mathrm{AlO}(\mathrm{OH})), 220-350{ }^{\circ} \mathrm{C}\right.$ for bayerite $\left(\alpha-\mathrm{Al}(\mathrm{OH})_{3}\right)$, and $360-520^{\circ} \mathrm{C}$ for boehmite $((\gamma-\mathrm{AlO}(\mathrm{OH})))^{36}$

293 For gibbsite $\left(\gamma-\mathrm{Al}(\mathrm{OH})_{3}\right)$, the removal of the hydroxyl groups occurred in two steps: between 260$294330{ }^{\circ} \mathrm{C}$ and $460-540{ }^{\circ} \mathrm{C} .{ }^{37}$ Within our system, it seems that $\mathrm{Al}_{13}$ and $\mathrm{GeAl}_{13}$ transition occur in the 295 region more aligned with boehmite or pseudoboehmite phases and the $\mathrm{GaAl}_{12}$ system transition 296 occurs closer to the transition for amorphous $\mathrm{Al}(\mathrm{OH})_{3}$ or bayerite. Interestingly, the general order 
297 of solubility at room temperature is gibbsite < boehmite < bayerite, which aligns with the relative 298 amount of precipitate that was formed from the $\mathrm{MAl}_{12}$ system $^{38}$.

Our TGA results align well with previously literature results regarding the precipitation of solid phases from the $\mathrm{Al}_{13}$ Keggin system. During aging, the original $\varepsilon-\mathrm{Al}_{13}$ phase can first transform into soluble oligomeric species (e.g. $\mathrm{Al}_{26}, \mathrm{Al}_{30}$ ) and then form insoluble $\mathrm{Al}(\mathrm{OH})_{3}$ precipitates. ${ }^{39,40}$ The exact nature of the solid precipitate that is formed from this process is dependent on the exact solution conditions. When an unhydrolyzed $\mathrm{Al}^{3+}$ solution is aged at higher temperature (which likely results in the formation of Keggin species, the precipitate that forms is 305 believed to be poorly crystalline pseudoboehmite $(\mathrm{AlO}(\mathrm{OH})){ }^{5}$ Similarly alumina sol-gels that contain $\mathrm{Al}_{13}$ Keggin species have also been shown to create a pseudoboehmite solid phase upon aging 5 . Hsu evaluated the room temperature aging of $\mathrm{Al}_{13}$ solution created through the addition of carbonate as the hydrolyzing agent and observed that the resulting precipitation in this case was crystalline gibbsite $\left(\mathrm{Al}(\mathrm{OH})_{3}\right){ }^{40}$ For this system the author suggested that the mechanism of gibbsite formation began with the breakdown of the $\mathrm{Al}_{13}$ polycations into monomeric specie,

311 which could then rearrange to form the gibbsite structure. Non-classical mechanisms that results 312 from structural transformation of the oligomeric phases may also be at play in the transition of an amorphous flocculant into a crystalline phase..$^{41-45}$

With the inclusion of the heteroatom, we do see differences in the second weight loss step that may suggest subtle differences in the resulting phase and this is supported by previous 316 studies within $\mathrm{Fe}^{3+}$ systems. Similar to $\mathrm{Al}^{3+}$ chemistry, $\mathrm{Fe}^{3+}$ also undergoes hydrolysis reaction in 317 aqueous systems and will rapidly precipitate amorphous or poorly crystalline nanoparticulate 318 phases that can contain a significant fraction of non-stoichiometric dopants ${ }^{46,47}$. If we look specifically at $\mathrm{Al}^{3+}$ as the dopant, previous studies have shown that $\mathrm{Fe}^{3+}$ will readily form a solid- 
320 solution series with an upper limit of $30 \% \mathrm{Al}^{3+}$ substitution ${ }^{46,48-50}$. Phase transformations for these

$321 \mathrm{Al}^{3+}$ doped materials vary depending on the presence of the heteroatom in the system. For instance,

$322 \mathrm{Al}^{3+}$ doped ferrihydrite will fav or the formation of hematite over goethite. Adding $\mathrm{Al}^{3+}$ to goethite

323 will also cause a systematic shift in the temperature region associated with the removal of hydroxyl

324 groups, which is similar to the region that is associated with the $\mathrm{GaAl}_{12}$ and $\mathrm{GeAl}_{12} \mathrm{systems}^{47}$. The

325 transformational changes observed with $\mathrm{Al}^{3+}$ doping within $\mathrm{Fe}^{3+}$ mineral phases suggest that we

326 should expect similar variability to occur within the $\mathrm{GaAl}_{12}$ and $\mathrm{GeAl}_{12}$ sy stems and supports our

327 current TGA results. 0

328

329

330

331

332

\section{Water treatment: Removal of DOC and Turbidity from Iowa River Water Samples}

Removal efficiency of DOC from aged and unaged $\mathrm{MAl}_{12}$ solutions was determined to be $\mathrm{pH}$ dependent, where the $\%$ removal for all $\mathrm{MAl}_{12}$ solutions increase with decreasing $\mathrm{pH}$. This result aligns well with previous work reported by Zhang et al. 2008 as they also found that humic acid removal by $\mathrm{PACl}-\mathrm{Al} 30$ increased as the has the $\mathrm{pH}$ of the solutions were lowered from 9 to $4^{51}$. They suggested that the labile protons on the surface of the Keggin species in the coagulant enables significant charge-neutralization of the humic acid, which destabilizes the macromolecule and allows flocculation to occur. Additionally, the stability of the Keggin species in solution is optimal at a pH of 4-5; thus, higher $\mathrm{pH}$ values may have competition between charge neutralization of the DOC and continued metal hydrolysis of the soluble clusters.

Subtle differences are observed in \% DOC removal that can be related to the heteroatom substitution and aging time. For unaged solution, $\mathrm{GaAl}_{12}$ performed slightly better in higher $\mathrm{pH}$ (7-9), followed by $\mathrm{Al}_{13}$ and $\mathrm{GeAl}_{12}$. At $\mathrm{pH} 5$ and 6, unaged $\mathrm{GeAl}_{12}$ had the highest \% DOC removal followed by $\mathrm{Al}_{13}$ and $\mathrm{GeAl}_{12}$. Aging time increases the \% $\mathrm{DOC}$ removal for $\mathrm{Al}_{13}$ and $\mathrm{GaAl}_{12}$, with an exception of $\mathrm{Al}_{13}$ solution at $\mathrm{pH} 9$ where we observe a decrease. The $\mathrm{GeAl}_{12}$ solutions display a different trend, with an initial increase in \% removal after one day aging, followed by a 
344 systematic decrease for 3 and 7 day aging. We note that the $\mathrm{GeAl}_{12}$ solutions also displayed the 345 greatest amount of precipitant formed upon aging, so this may also account for the decrease in the 346 overall efficiency observed in this system. 


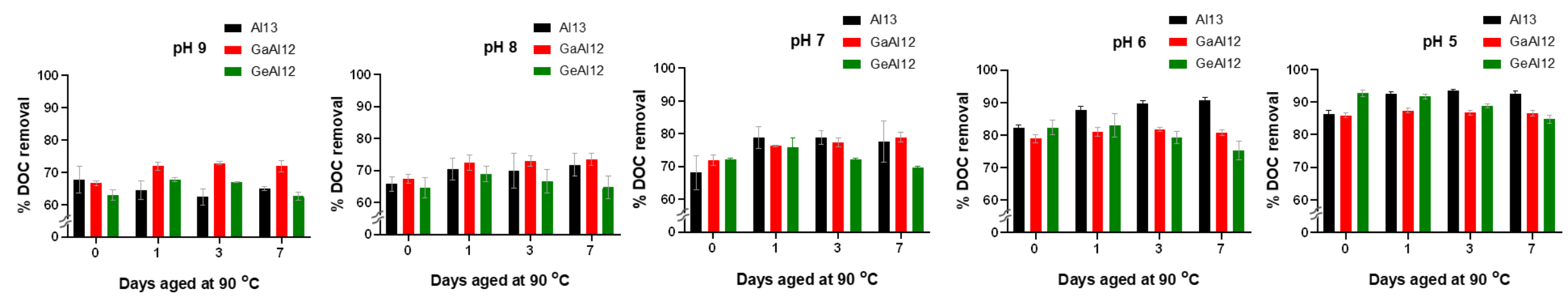

Figure 4. DOC removal efficiency of unaged and aged $\mathrm{MAl}_{12}$ solutions from humic acid spiked Iowa river water at different $\mathrm{pH}$. 
Trends related to the turbidity removal efficiency for kaolin spiked Iowa river water using 353 the $\mathrm{MAl}_{12}$ solutions are less clear than those observed for \% DOC. The turbidity removal 354 efficiency of most solutions was lower when the $\mathrm{pH}$ was decreased from 9 to 7 , but the turbidity 355 removal from $\mathrm{pH} 7$ to 5 does not follow a clear pattern. For example, a turbidity removal efficiency 356 increased between a pH 7 to 6 , but decreased when we moved from pH 6 to 5 . In general, 1 to 3 357 days aging increased the turbidity removal efficiency of $\mathrm{MAl}_{12}$ solutions at different $\mathrm{pH}$, but 7 358 days aging mostcases decreases the efficiency. When comparing effect of heteroatom substitution 359 in unaged solution, $\mathrm{Al}_{13}$ or $\mathrm{GeAl}_{12}$ demonstrated better turbidity removal compared to $\mathrm{GaAl}_{12}$ at 360 higher $\mathrm{pH}$ (9 to 8). But at lower $\mathrm{pH}$ (7 to 5), the turbidity removal efficiency trends were $\mathrm{GaAl}_{12}$ $361>\mathrm{GeAl}_{12}>\mathrm{Al}_{13}$. For aged solution, $\mathrm{GaAl}_{12}$ showed superior performance followed by $\mathrm{GeAl}_{12}$ and $362 \mathrm{Al}_{13}$ at most $\mathrm{pH}$ ranges. Interestingly $\mathrm{pH} 9$ was the exception because the $\mathrm{GeAl}_{12}$ solution 363 demonstrated higher efficiency in turbidity removal. The aged $\mathrm{GaAl}_{12}$ solutions consistently 364 removed turbidity at all $\mathrm{pH}$ ranges and this is specifically apparent at $\mathrm{pH} 5$, where the aged $\mathrm{GaAl}_{12}$ 365 solutions showed remarkably high turbidity removal performance compared to other solutions. 


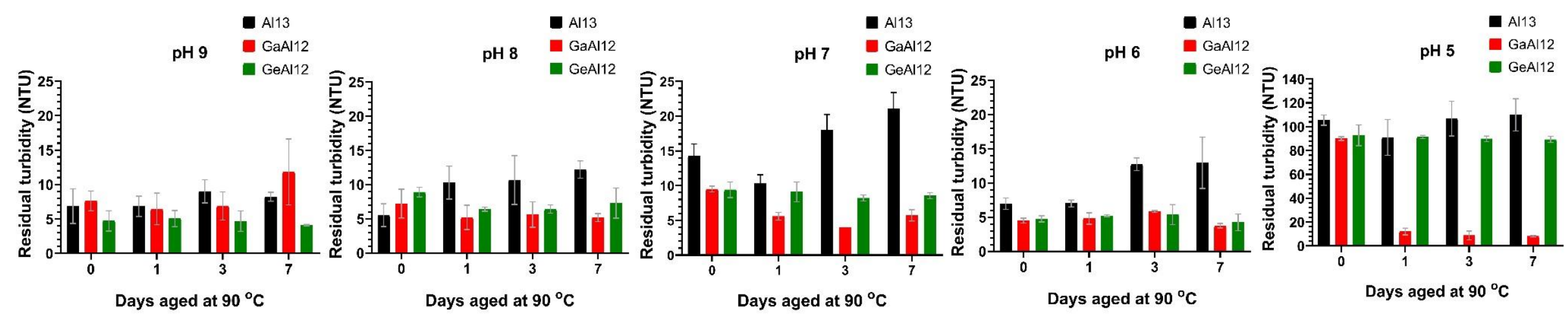

Figure 5. Turbidity removal efficiency of unaged and aged $\mathrm{MAl}_{12}$ solutions through residual turbidity measurement of kaolin spiked Iowa river water at different $\mathrm{pH}$. 
Our results suggesting that heteroatom substitutions in $\mathrm{Al}_{13}$ and subsequent hydrothermal aging have significant impact in their water treatment efficiency with respect to DOC and turbidity

373 removal. We have observed that although at higher $\mathrm{pH}$ the water treatment efficiency of $\mathrm{GaAl}_{12}$ is 374 better than $\mathrm{Al}_{13}$ and $\mathrm{GeAl}_{12}$, this trend does not hold true for lower $\mathrm{pH}$ values for $\mathrm{DOC}$ removal. 375 Turbidity removal of the $\mathrm{GaAl}_{12}$ aged and unaged solutions display superior capability in all $\mathrm{pH}$ 376 range (9-5) compared to other $\mathrm{MAl}_{12}$ solutions, with the highest performance observed at $\mathrm{pH} 5$. Previous work by Stewart et al. 2009, indicated that the $\mathrm{GaAl}_{12}$ stock solution performed 378 better in water treatment due to its relative stability, lower acidity, and tendency not to form larger 379 clusters and oligomers. ${ }^{15}$ The turbidity and gravimetric experiment from our study also showed 380 relative stability of $\mathrm{GaAl}_{12}$ with respect to the transformation of polyaluminum species into $381 \mathrm{Al}(\mathrm{OH})_{3}$ based precipitate. Our DLS experiment also showed similar particle size distribution for 382 polyaluminum species in unaged to 3 days aged $\mathrm{GaAl}_{12}$ solution which maybe an indication of 383 stability and less oligomerization behavior. When the article by Stewart et al. was published in 3842009 , there was no experimental evidence that larger oligomers with the $\mathrm{GaAl}_{12}$ system existed, 385 but more recent efforts suggested that $\mathrm{Ga}_{2.5} \mathrm{Al}_{28.5}$ and $\mathrm{Ga}_{2} \mathrm{Al}_{18}$ do occur in aged solutions. ${ }^{15}$ These 386 newer species having different charge, size and surface characteristic than the $\varepsilon$-Keggin and may 387 have better capability to neutralize the contaminant and without destabilizing the clusters from 388 solution. For example, solutions containing $\mathrm{Al}_{30}$ polyaluminum clusters demonstrated higher floc 389 formation capacity than $\mathrm{Al}_{13}$ bearing solutions and this was linked to a higher number of adsorption 390 sites, more neutralization capacity, and better solution stability (temperature and $\mathrm{pH}$ ). ${ }^{12}$ Owing to 391 those physicochemical changes, $\mathrm{Al}_{30}$ is a better turbidity removal agent at wider $\mathrm{pH}$ range then $392 \mathrm{Al}_{13}$. This suggests that the presence of $\mathrm{Ga}_{2.5} \mathrm{Al}_{28.5}$ and $\mathrm{Ga}_{2} \mathrm{Al}_{18}$ could also enhance the removal of 393 DOC and turbidity from natural water samples. 


\section{Conclusion}

In conclusion, our study demonstrated that heteroatom substitution in $\varepsilon-\mathrm{Al}_{13}$ have profound

396 impact on their transformation into other polyaluminum species and insoluble hydroxides. Overall,

397 the $\mathrm{GaAl}_{12}$ solution was more stable during thermal aging than $\mathrm{Al}_{13}$ or $\mathrm{GeAl}_{12}$ and DLS results

398 indicated that this system possessed more diversity within the soluble particle size. In addition,

399 the resulting precipitant form the aging study for $\mathrm{GaAl}_{12}$ was found to behave in a similar manner

400 upon heating and may contain structural features with similarities to amorphous $\mathrm{Al}(\mathrm{OH})_{3}$ or

401 bayerite phase, which is known to have higher solubility than other $\mathrm{Al}^{3+}$ phases. This chemical

402 transformation governs the stability of soluble species and their coagulation performance,

403 including the formation of larger oligomers that may increase \% DOC and turbidity removal.

$404 \quad$ Results from present work will shed new light on the development of highly effective 405 aluminum-oxo Keggin polycation based coagulants. The difference in water treatment efficiency 406 of different heteroatom-substituted and aged Keggin solution pointing towards importance of 407 further investigations to identify the different possible oligomers that may be present in the system.

408 Overall, the relatively coagulation efficiency may depend on a smaller number of more reactive 409 species to achieve the systems level observables that are measured during experimental evaluation 410 of flocculation behavior and contaminant removal. Continued advancements in understanding of 411 the fundamental changes to surface chemistry and stability of both pure and doped Keggin-type 412 polyaluminum coagulants can lead to a targeted approached toward water purification efforts. 

contains additional images and results of turbidity measurement, PXRD analysis and SEM-EDS

417 analysis.

\section{Author Contributions}

421 treatment experiments, and prepared initial draft of the study. JAS prepared $\mathrm{MAl}_{12}$ solutions, 422 performed water treatment experiments and contributed in writing initial draft. MAC helped with 423 turbidity experiment. TZF provided resources, guided conceptualization of the study, ensured 424 method validation, and edited the manuscript. All author contributed in preparation and revision 425 of the manuscript.

427 Notes

428 The authors declare no conflict of interest.

430 Acknowledgement

431 We acknowledge Prof. Aliasger Salem and Dr. Lr Jaidev Chakka (UIowa college of 432 Pharmacy) for their help regarding DLS experiment. We also acknowledge help of Phil Pagano 433 (Center for Research, Exploration, and Advanced Technology in Engineering and Sciences, Iowa 434 CREATES) for his help with SEM-EDS analysis. We thank Prof. Craig L. Just (UIowa, Civil and 435 Environmental Engineering) to let us use the turbidity meter. 
1. EPA National Pollutant Discharge Elimination System Permit Writer's Manual: Chapter 5 Technology-Based Effluent Limitations https://www.epa.gov/npdes/npdes-permit-writers-manual (accessed 10/06/2020).

442 2. Standard methods: for the examination of water and wastewater. American Public Health

443 Association: Washington, D.C, 1989; p 10200.

$444 \quad 3 . \quad$ Casey, W. H., Large Aqueous Aluminum Hydroxide Molecules. Chem. Rev. 2006, 106 (1), 1-16.

445 4. Abeysinghe, S.; Unruh, D. K.; Forbes, T. Z., Crystallization of Keggin-Type Polyaluminum Species

446 by Supramolecular Interactions with Disulfonate Anions. Crystal Growth \& Design 2012, 12 (4), $2044-$ 2051.

5. Fu, G.; Nazar, L. F.; Bain, A. D., Aging processes of alumina sol-gels: characterization of new aluminum polyoxycations by aluminum-27 NMR spectroscopy. Chem. Mater. 1991, 3 (4), 602-610.

6. Furrer, G.; Phillips, B. L.; Ulrich, K.-U.; Pöthig, R.; Casey, W. H., The Origin of Aluminum Flocs in Polluted Streams. Science 2002, 297 (5590), 2245.

452 7. Sahu, O.; Chaudhari, P., Review on Chemical treatment of Industrial Waste Water. Journal of 453 Applied Sciences and Environmental Management 2013, 17 (2), 241-257.

$454 \quad$ 8. Sinha, S.; Yoon, Y.; Amy, G.; Yoon, J., Determining the effectiveness of conventional and alternative coagulants through effective characterization schemes. Chemosphere 2004, 57 (9), 11151122.

457 9. MWH's water treatment: principles and design. 3rd ed ed.; John Wiley \& Sons: Hoboken, N.J, $458 \quad 2012 ; \mathrm{p} 1901$.

459 10. Kweinor Tetteh, E.; Rathilal, S., Application of Organic Coagulants in Water and Wastewater 460 Treatment. In Organic Polymers, Sand, A.; Zaki, E., Eds. IntechOpen: 2020.

461 11. Mertens, J.; Casentini, B.; Masion, A.; Pöthig, R.; Wehrli, B.; Furrer, G., Polyaluminum chloride with high Al30 content as removal agent for arsenic-contaminated well water. Water Res. 2012, 46 (1), 53-62.

12. Chen, Z.; Fan, B.; Peng, X.; Zhang, Z.; Fan, J.; Luan, Z., Evaluation of Al30 polynuclear species in polyaluminum solutions as coagulant for water treatment. Chemosphere 2006, 64 (6), 912-918.

13. Yan, M.; Wang, D.; Qu, J.; He, W.; Chow, C. W. K., Relative importance of hydrolyzed Al(III) species (Ala, Alb, and Alc) during coagulation with polyaluminum chloride: A case study with the typical micro-polluted source waters. J. Colloid Interface Sci. 2007, 316 (2), 482-489.

14. Matsui, Y.; Matsushita, T.; Sakuma, S.; Gojo, T.; Mamiya, T.; Suzuoki, H.; Inoue, T., Virus Inactivation in Aluminum and Polyaluminum Coagulation. Environmental Science \& Technology 2003, 37 (22), 5175-5180.

15. Stewart, T. A.; Trudell, D. E.; Alam, T. M.; Ohlin, C. A.; Lawler, C.; Casey, W. H.; Jett, S.; Nyman, M., Enhanced Water Purification: A Single Atom Makes a Difference. Environmental Science \& Technology 2009, 43 (14), 5416-5422.

16. Wu, Z.; Zhang, X.; Pang, J.; Zhang, X.; Li, J.; Li, J.; Zhang, P., Humic Acid Removal from Water with PAC-Al30: Effect of Calcium and Kaolin and the Action Mechanisms. ACSOmega 2020, 5 (27), 16413-16420.

17. Demissie, H.; An, G.; Jiao, R.; Ritigala, T.; Lu, S.; Wang, D., Modification of high content nanocluster-based coagulation for rapid removal of dye from water and the mechanism. Sep. Purif. Technol. 2021, 259, 117845.

18. Lu, S.; Liu, L.; Yang, Q.; Demissie, H.; Jiao, R.; An, G.; Wang, D., Removal characteristics and mechanism of microplastics and tetracycline composite pollutants by coagulation process. Sci. Total Environ. 2021, 786, 147508.

484 19. Parker, W. O. N.; Millini, R.; Kiricsi, I., Metal Substitution in Keggin-Type Tridecameric Aluminum-Oxo-Hydroxy Clusters. Inorg. Chem. 1997, 36 (4), 571-575. 
20. Lee, A. P.; Phillips, B. L.; Olmstead, M. M.; Casey, W. H., Synthesis and Characterization of the GeO4Al12(OH)24(OH2)128+ Polyoxocation. Inorg. Chem. 2001, 40 (17), 4485-4487.

21. Shohel, M.; Bjorklund, J. L.; Ovrom, E. A.; Mason, S. E.; Forbes, T.Z., Ga3+Incorporation into Al13 Keggin Polyoxometalates and the Formation of $\delta-(G a A l 12) 7+$ and (Ga2.5Al28.5)19+ Polycations. Inorg. Chem. 2020, 59 (15), 10461-10472.

22. Fairley, M.; Corum, K. W.; Johns, A.; Unruh, D. K.; Basile, M.; de Groot, J.; Mason, S. E.; Forbes, T. Z., Isolation and characterization of the [Ga2Al18O8(OH)36(H2O)12]8+ cluster: cationic variations on the Wells-Dawson topology. Chem. Commun. 2015, 51 (62), 12467-12469.

23. Shohel, M.; Bjorklund, J. L.; Smith, J. A.; Kravchuk, D. V.; Mason, S. E.; Forbes, T. Z., Formation of Nanoscale [Ge4O16Al48(OH)108(H2O)24]20+ from Condensation of $\epsilon$-GeAl128+ Keggin Polycations. Angew. Chem. Int. Ed. 2021, 60 (16), 8755-8759.

24. Bjorklund, J. L.; Shohel, M.; Bennett, J. W.; Smith, J. A.; Carolan, M. E.; Hollar, E.; Forbes, T. Z.; Mason, S. E., Density functional theory and thermodynamics analysis of MAl12 Keggin substitution reactions: Insights into ion incorporation and experimental confirmation. The Journal of Chemical Physics 2021, 154 (6), 064303.

25. Johansson, G.; Dorm, E.; Seleborg, M.; Motzfeldt, K.; Theander, O.; Flood, H., The Crystal Structures of $[\mathrm{Al} 2(\mathrm{OH}) 2(\mathrm{H} 2 \mathrm{O}) 8](\mathrm{SO} 4) 2.2 \mathrm{H} 2 \mathrm{O}$ and $[\mathrm{Al} 2(\mathrm{OH}) 2(\mathrm{H} 2 \mathrm{O}) 8](\mathrm{SeO}) 2.2 \mathrm{H} 2 \mathrm{O}$. Acta chemica Scandinavica. 1962, 16, 403-420.

26. Lin, J.-L.; Huang, C.; Chin, C.-J. M.; Pan, J. R., The origin of Al(OH)3-rich and Al13-aggregate flocs composition in PACl coagulation. Water Res. 2009, 43 (17), 4285-4295.

27. Lin, J.-L.; Huang, C.; Pan, J. R.; Wang, D., Effect of Al(III) speciation on coagulation of highly turbid water. Chemosphere 2008, 72 (2), 189-196.

28. Weishaar, J. L.; Aiken, G. R.; Bergamaschi, B. A.; Fram, M. S.; Fujii, R.; Mopper, K., Evaluation of Specific Ultraviolet Absorbance as an Indicator of the Chemical Composition and Reactivity of Dissolved Organic Carbon. Environmental Science \& Technology 2003, 37 (20), 4702-4708.

29. Lee, A. P.; Furrer, G.; Casey, W. H., On the Acid-Base Chemistry of the Keggin Polymers: GaAl12 and GeAl12. J. Colloid Interface Sci. 2002, 250 (1), 269-270.

30. Bjorklund, J. L.; Bennett, J. W.; Forbes, T. Z.; Mason, S. E., Modeling of MAl12 Keggin Heteroatom Reactivity by Anion Adsorption. Crystal Growth \& Design 2019, 19 (5), 2820-2829.

31. Wishard, A.; Gibb, B. C., Dynamic light scattering - an all-purpose guide for the supramolecular chemist. Supramol. Chem. 2019, 31 (9), 608-615.

32. Stetefeld, J.; McKenna, S. A.; Patel, T. R., Dynamic light scattering: a practical guide and applications in biomedical sciences. Biophysical reviews 2016, 8 (4), 409-427.

33. Rowsell, J.; Nazar, L. F., Speciation and Thermal Transformation in Alumina Sols: Structures of the Polyhydroxyoxoaluminum Cluster [Al30O8(OH)56(H2O)26]18+ and Its $\delta$-Keggin Moieté. J. Am. Chem. Soc. 2000, 122 (15), 3777-3778.

34. Allouche, L.; Gérardin, C.; Loiseau, T.; Férey, G.; Taulelle, F., Al30: A Giant Aluminum Polycation. Angew. Chem. Int. Ed. 2000, 39 (3), 511-514.

35. Deschaume, O.; Breynaert, E.; Radhakrishnan, S.; Kerkhofs, S.; Haouas, M.; Adam de Beaumais, S.; Manzin, V.; Galey, J.-B.; Ramos-Stanbury, L.; Taulelle, F.; Martens, J. A.; Bartic, C., Impact of Amino Acids on the Isomerization of the Aluminum Tridecamer Al13. Inorg. Chem. 2017, 56 (20), 12401-12409.

36. Sato, T., The thermal transformation of Gelatinous Aluminium Hydroxide. Z. Anorg. Allg. Chem. 1972, 391 (2), 167-173.

37. Kloprogge, J.T.; Ruan, H. D.; Frost, R. L., Thermal decomposition of bauxite minerals: infrared emission spectroscopy of gibbsite, boehmite and diaspore. Journal of Materials Science 2002, 37 (6), 1121-1129. 
38. Bénézeth, P.; Hilic, S.; Palmer, D. A., The Solubilities of Gibbsite and Bayerite Below $100{ }^{\circ} \mathrm{C}$ in Near Neutral to Basic Solutions. J. Solution Chem. 2016, 45 (9), 1288-1302.

39. Allouche, L.; Taulelle, F., Conversion of Al13 Keggin $\varepsilon$ into Al30: a reaction controlled by aluminum monomers. Inorg. Chem. Commun. 2003, 6 (9), 1167-1170.

40. Hsu, P. H., Mechanisms of Gibbsite Crystallization from Partially Neutralized Aluminum Chloride Solutions. Clays Clay Miner. 1988, 36 (1), 25-30.

41. Hou, Y.; Zakharov, L. N.; Nyman, M., Observing Assembly of Complex Inorganic Materials from Polyoxometalate Building Blocks. J. Am. Chem. Soc. 2013, 135 (44), 16651-16657.

42. Demichelis, R.; Raiteri, P.; Gale, J. D.; Quigley, D.; Gebauer, D., Stable prenucleation mineral clusters are liquid-like ionic polymers. Nature Communications 2011, 2 (1), 590.

43. Dey, A.; Bomans, P. H. H.; Müller, F. A.; Will, J.; Frederik, P. M.; de With, G.; Sommerdijk, N. A. J. M., The role of prenucleation clusters in surface-induced calcium phosphate crystallization. Nature Materials 2010, 9 (12), 1010-1014.

44. Gebauer, D.; Kellermeier, M.; Gale, J. D.; Bergström, L.; Cölfen, H., Pre-nucleation clusters as solute precursors in crystallisation. Chem. Soc. Rev. 2014, 43 (7), 2348-2371.

45. Yang, X.; Wang, M.; Yang, Y.; Cui, B.; Xu, Z.; Yang, X., Physical origin underlying the prenucleation-cluster-mediated nonclassical nucleation pathways for calcium phos phate. PCCP 2019, 21 (27), 14530-14540.

46. Cornell, R. M.; Schwertmann, U., The Iron Oxides: Structure, Properties, Reactions, Occurences and Uses. 1 ed.; Wiley: 2003.

47. Pinney, N.; Morgan, D., Thermodynamics of Al-substitution in Fe-oxyhydroxides. Geochim. Cosmochim. Acta 2013, 120, 514-530.

48. Lewis, D. G.; Schwertmann, U., The Influence of Aluminum on the Formation of Iron Oxides. IV. The Influence of [Al], [OH], and Temperature. Clays Clay Miner. 1979, 27 (3), 195-200.

49. Schwertmann, U., Occurrence and Formation of Iron Oxides in Various Pedoenvironments. In Iron in Soils and Clay Minerals, Stucki, J. W.; Goodman, B. A.; Schwertmann, U., Eds. Springer Netherlands: Dordrecht, 1988; pp 267-308.

50. Scheinost, A. C.; Schulze, D. G.; Schwertmann, U., Diffuse Reflectance Spectra of Al Substituted Goethite: A Ligand Field Approach. Clays Clay Miner. 1999, 47 (2), 156-164.

51. Zhang, P.; Wu, Z.; Zhang, G.; Zeng, G.; Zhang, H.; Li, J.; Song, X.; Dong, J., Coagulation characteristics of polyaluminum chlorides PAC-Al30 on humic acid removal from water. Sep. Purif. Technol. 2008, 63 (3), 642-647. 